\title{
Effect of cementitious amendment on the hydrogeological behavior of a surface paste tailings' disposal
}

\author{
Hadimi Ichrak $^{1} \cdot$ Benzaazoua Mostafa $^{1} \cdot$ Maqsoud Abdelkabir $^{1} \cdot$ Bussière Bruno $^{1}$
}

Received: 1 April 2016/Accepted: 20 June 2016/Published online: 6 July 2016

(C) Springer International Publishing Switzerland 2016

\begin{abstract}
Surface paste disposal (SPD) can be considered as an effective alternative technique for mine waste management. The technique consists of first removing upstream water (by thickening and/or filtration) from tailings, then depositing them at the surface in a paste-like state. These techniques allow for the recycling of water, limit risks related to the failure of dikes, and favor progressive mine site rehabilitation. However, there are, thus far, only a few studies on the environmental behavior of tailings deposited using the SPD technique. To evaluate the hydrogeological and geochemical behaviors of a sulphidic tailings' deposit simulating the SPD method, a laboratory study was performed using a physical model. Paste tailings were prepared and deposited inside the physical model in nine layers. In the first stage, only the first two bottom layers were amended with cement $(2 \% \mathrm{w} / \mathrm{w}$ of PC10 Portland cement). The physical model was then subjected to wetting and drying cycles, and the water collected after each flush was analysed for chemistry and its volume was measured. At the end of the 27th cycle, a tenth layer of cemented tailings was deposited on the top of the tailings' stack. Testing was performed for 34 cycles, and then, the model was dismantled and the collected samples were analysed through a multidisciplinary fine characterisation. The results of this investigation showed that the volume of collected water at the bottom of the physical model varied over the test's duration. This could be due to seasonal variations in the temperature and moisture of the
\end{abstract}

Maqsoud Abdelkabir

abdelkabir.maqsoud@uqat.ca

1 Research Institute on Mines and Environment (RIME), Université du Quebec en Abitibi-Temiscamingue (UQAT), 445 University Blvd, Rouyn-Noranda, QC J9X 5E4, Canada laboratory. The cemented layer deposited on the top of the physical model appears to play the role of protecting against underlying layers from evaporation. Finally, diffuse oxidation that progressed along the preferential pathway was observed.

Keywords Surface paste disposal $\cdot$ Physical model · Acid mine drainage $\cdot$ Hydrochemical $\cdot$ Hydrogeological behavior

\section{Introduction}

Ore extraction generates a large amount of liquid and solid wastes. Solid mine wastes are principally comprised of the uneconomic waste rocks which are extracted to reach the ore body and wastes from ore processing plants. When these wastes are not properly managed during a mine's exploitation and after its closure, the potential to adversely impact the environment is high. Particular attention is required when these wastes contain sulphide minerals, such as pyrite and pyrrhotite. The exposure of these sulphide minerals to atmospheric oxygen results in their oxidation and the acidification of surface waters [5, 22, 25, 26, 34]; this phenomenon is known as acid mine drainage (AMD) or acid rock drainage (ARD). In cases where mine wastes contain carbonate minerals, a partial or complete neutralization of the acidic water is possible [5]. However, when the acid neutralization potential is not sufficient or has been exhausted, AMD occurs and can mobilize some of the elements contained in the wastes due to the increased solubility of certain elements at low $\mathrm{pH}$ [5]. In these situations, actions must be taken at the mine site to prevent environmental impacts caused by AMD production.

To properly manage mine wastes, hydraulic fill or rock fill is used for the filling of underground mine workings. 
Recently and during the two past decades, cemented paste mining backfill has emerged as an alternative for underground filling (e.g., $[9,10,21])$; however, despite increasing underground waste management, there remains a significant amount of tailings that must be stored on the surface around the mine site (tailings' impoundment). The most conventional technique is for managing mill tailings is currently to store them in the form of a pulp, i.e., with a solid content less than approximately $50 \%$. Unfortunately, this method requires the construction of dikes which can be costly and difficult to maintain in the long term (see $[6,18,23])$. This conventional disposal technique could potentially be replaced by an alternative technique, surface paste disposal (SPD), which would thicken and filter mill tailings to give a gravimetric water content between 15 and $25 \%$ and a solid content of approximately $80-85 \%$. The resulting filter cake can be amended with a small percentage of cement (optionally with about $75 \%$ pulp) to improve physical and chemical stabilities. Given that this technique allows for the recycling of water, eliminates the need for expensive containment dikes, and facilitates mine site reclamation, SPD may be an interesting viable alternative to conventional tailings' disposal.

The SPD technique was applied for the first time at the Bulyanhulu mine in Tanzania [27, 30-32, 36, 37]; MEND, $[1-3,16,28,35]$. The paste had a solid content of $73 \%$, which corresponds to $250 \mathrm{~mm}$ measured at the cone of Abraham slump [4]. The deposition, which had a slope of approximately $5^{\circ}$, was performed at a rate of one layer every 5 days; each layer had a maximum thickness of $30 \mathrm{~cm}$ [36]. The SPD technique has also been evaluated using experimental field cells [7, 24, 39].

In this study, the hydrogeological and geochemical behaviors of tailings deposited using the SPD technique were examined using a physical model, in which its efficiency to monitor paste tailings' disposal was validated previously [11]. This model was filled in the first stage with nine layers of tailings. Initially, only the lowest two layers were cemented with $2 \%$ w/w of PC10 Portland cement. The tailings were then rinsed every 4 weeks with $40 \mathrm{~L}$ of tap water. After 14 wetting/drying cycles, the results of hydrogeological and hydrochemical analyses were published by Deschamps et al. [15]. This article complements the prior study by presenting long-term measurements and data on the influence of a final cemented layer at the surface of the model.

The main objectives of this study are: (1) to better understand the long-term environmental behavior of the tailings deposited using the SPD technique and (2) to understand the effect of adding small quantities of binder on reducing sulphide oxidation. The specific objectives of this research project are:
- To study the long-term hydrogeochemical behavior of the existing instrumented physical model. The focus here is to better characterize the evolution of the hydrogeological properties of the layers of paste in the deposit (cemented or not);

- To assess the influence of the addition of a surface cemented layer and to study its effect on the hydrogeological behavior of paste;

- To characterize the materials in the physical model at the post-testing stage and to better understand the evolution of the hydrogeological and geochemical properties of the SPD during the tested period.

This paper presents data on the behavior of the paste during the wetting/drying cycles and on the materials characterization of the paste following the dismantling of the physical model.

\section{Materials and methods}

\section{Tailings' physical characterization methods}

The main techniques used for the analysis of solid samples are presented in the following sections.

\section{Particle size and specific gravity}

The grain-size distribution of the tailings was measured with a Mastersizer Standard Type S laser diffraction particle size analyser (Malvern Instruments). A helium pycnometer (AccuPyc 1330 from Micrometrics) was used to measure the specific gravity $\left(G_{\mathrm{s}}\right)$ of the solid grains.

\section{Mercury intrusion porosimetry}

The total porosity and the pore-size distribution were determined by mercury intrusion porosimetry (MIP). MIP measurements were performed using a Micromeritics AutoPore III Model 9420 mercury porosimeter which generates a highest applied pressure of $414 \mathrm{MPa}$ and can evaluate a lowest pore access diameter of $0.003 \mu \mathrm{m}$. Each sample was oven-dried for $48 \mathrm{~h}$ at $40{ }^{\circ} \mathrm{C}$ prior to the analysis, which was conducted according to the optimized technique developed by Ouellet et al. [29].

\section{Scanning electron microscopy}

A Hitachi ${ }^{\circledR} 3500-\mathrm{N}$ scanning electron microscope coupled with energy dispersive X-ray spectroscopy (SEM-EDS, Oxford Instrument link ISIS, UK) was used to examine the 
microstructure and the chemical composition of the paste samples.

\section{Devices and test}

\section{Physical model}

The physical model (a Lexan, transparent plastic box, reinforced by a metal frame) was $200 \mathrm{~cm}$ (length) by $50 \mathrm{~cm}$ (width) by $100 \mathrm{~cm}$ (height) (Fig. 1a). The box was mounted on a plate at the bottom and equipped with a draining system covered by a geotextile to prevent the loss of solid particles. Water was allowed to drain at the bottom of the model, so that leachates could be collected for geochemical analyses.

The paste tailings used in the physical model test were prepared from filtered tailings mixed with tap water to obtain the desired paste consistency. A $250 \mathrm{~mm}$ slump was targeted based on the work of Theriault et al. [36]. This slump value corresponds to a solid content of $74 \%$.

In the first stage, nine layers were deposited inside the physical model. Only the two lowest layers contained $2 \%$ w/w of PC10 cement. In the second stage, and just before the 28th cycle, a tenth cemented layer ( $2 \%$ w/w PC10) was added as cover at the very top of the stack. The tailings used for the preparation of the tenth cemented layer were the same as those used for the first nine layers. Each layer was approximately $4 \mathrm{~cm}$ thick, and instrumented using a TDR (time domain reflectometry) sensor (placed horizontally in the middle of the layer) to monitor volumetric water content
(VWC). For the tenth layer, an $\mathrm{ECH}_{2} \mathrm{O}$ probe was also placed horizontally in the middle of the layer (Fig. 1b) for volumetric water content measurements. The second layer was deposited inside the model 7 days after the first one. Subsequently, the frequency of addition of other layers was 2-3 days. Finally, after completing 27 wetting/drying cycles, a last (tenth) layer was added to the stack.

\section{Monitoring of the physical model test: wetting/drying tests}

Four weeks after the deposition of the ninth layer, wetting/ drying cycles were performed [14]. During each wetting/ drying cycling, wetting was performed over 2 days. The model was then allowed to dry for a period of approximately 26 days to achieve hydrogeological equilibrium, as well as to allow for the percolation of water and favor a maximum reactivity of SPD. On average, a wetting/drying cycle lasted 4 weeks.

During the wetting/drying cycles, the volume of water drained from the physical model was collected and measured. The volumetric water content at the level of each layer was also measured using the TDR probes installed in the middle of these layers [14]. At the end of each drying period, but prior to the next wetting period, aerial pictures of the paste stack's surface were taken to track the evolution of the desiccation of the surface layer.

After the 14th wetting period, it was decided to extend the drying period by an additional 2 weeks to simulate the influence of a longer drying period on the behavior of the tailings in the physical model.

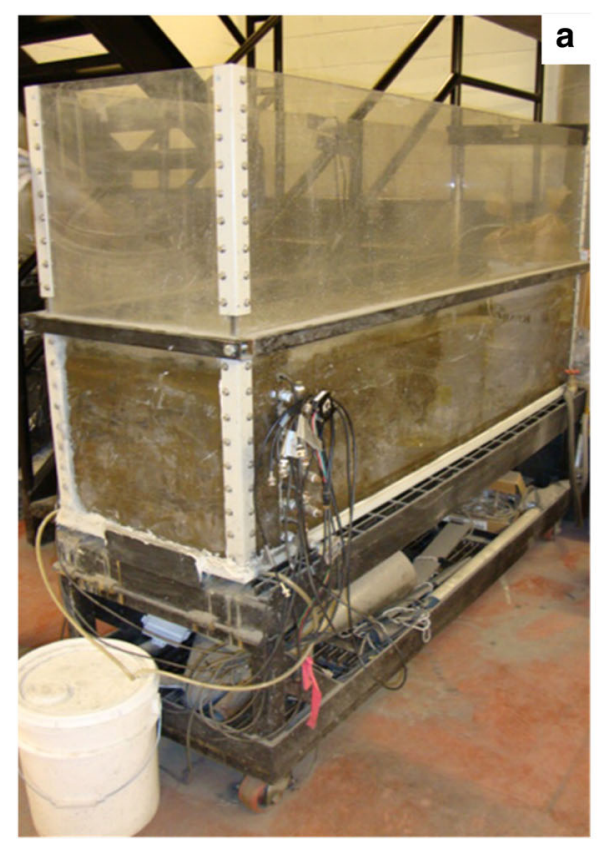

$40 \mathrm{~cm}$

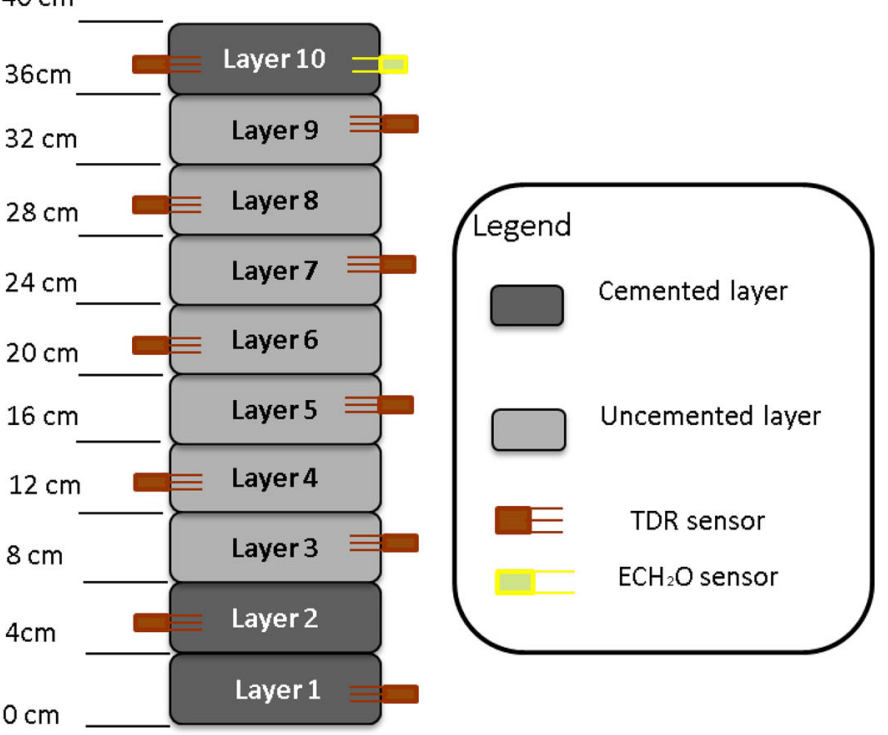

Fig. 1 a Photo of the physical model. b Diagram showing the TDR and the $\mathrm{ECH}_{2} \mathrm{O}$ sensors and layer thicknesses 


\section{Dismantling the physical model}

At the end of the wetting/drying cycles (after 34 cycles), the physical model was dismantled. Photos illustrating the main macroscopic observations were taken during the dismantling operation, and analyses were subsequently performed on solid samples collected from preselected locations in the physical model. The paste samples were characterized by mercury intrusion porosimetry (MIP) and scanning electron microscope (SEM) coupled with energy dispersive spectroscopy (EDS) microanalysis.

\section{Results}

\section{Tailings’ characterization}

The grain-size distribution of the homogenized tailings used in this study (Fig. 2) was typical of the tailings that result from mineral processing, before their deposition in an impoundment $[5,8,13] . D_{10}$ (diameter at which $10 \%$ of particles pass) was about $2.9 \mu \mathrm{m}, D_{50}$ was $27 \mu \mathrm{m}$, and $D_{90}$ was $105 \mu \mathrm{m}$ (Table 1 ). The specific gravity $\left(G_{\mathrm{s}}\right)$ of the solids was 3.12, and was influenced heavily by sulphur content.

Microstructural analysis by mercury intrusion porosimetry (MIP) of cemented paste samples revealed a total porosity of $46.6 \%$, whereas the porosity of the uncemented paste was $40.3 \%$ (Fig. 3). This difference is mainly due to the fact that the addition of cement reduced

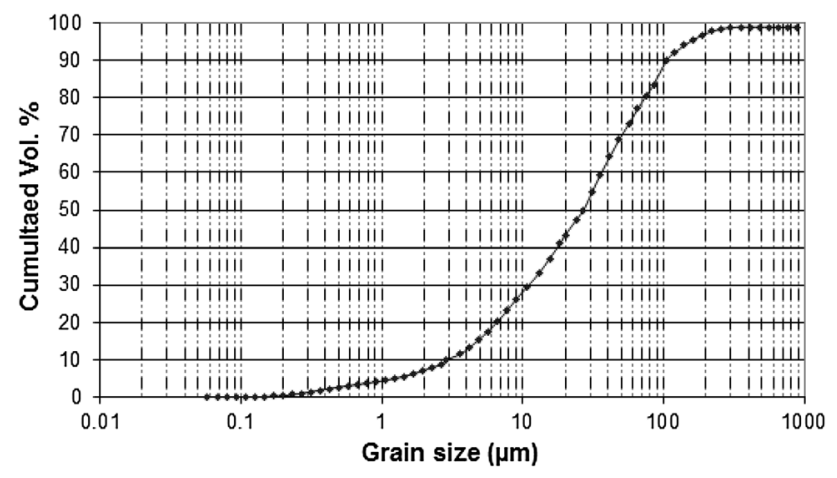

Fig. 2 Grain-size distribution of tailings

Table 1 Main physical characteristics of the tailings (from [14]

\begin{tabular}{ll}
\hline Physical parameters & Value \\
\hline Specific gravity: $G \mathrm{~s}$ & 3.12 \\
$D_{10}(\mu \mathrm{m})$ & 2.9 \\
$D_{50}(\mu \mathrm{m})$ & 27 \\
$D_{90}(\mu \mathrm{m})$ & 105 \\
\hline
\end{tabular}

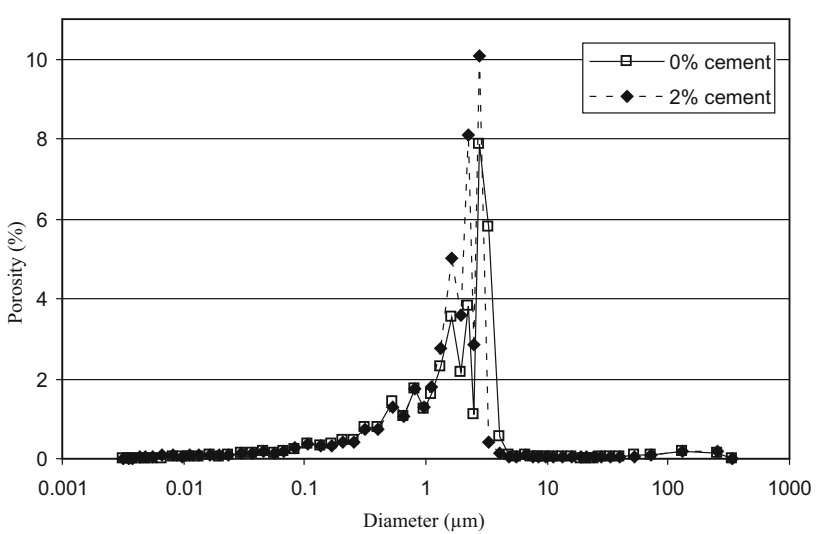

Fig. 3 MIP incremental curve of past tailings after 28 days of cures (adapted from [14])

the density of paste and induced nano-porosity through the presence of hydrates and precipitated cementitious phases [38]. However, the threshold diameter was lower in cemented paste samples $(3.3 \mu \mathrm{m})$ than those in uncemented paste $(4.1 \mu \mathrm{m})$, and, thus, the addition of cement reduced the pore size of the paste (also observed by [29].

\section{Volume of water collected at the bottom of the physical model}

During the initial wetting/drying cycles, the volume of water collected from the physical model was highly variable (Fig. 4). A gradual increase in the drained volume of water was observed from the 7 th to 14 th cycles $(1-12 \mathrm{~L})$. After the 14th drying period, at the 15 th cycle, a drastic fall in the collected volume of water was observed. A second increase in the volume of drained water was observed between the 16 th to 22 nd cycles; at this time, the volume increase was more drastic (from 0.5 to $25.5 \mathrm{~L}$ ). Subsequently, there was a gradual decline in the volume of collected water until after the deposition of the tenth cemented layer when the volume of collected water after each wetting cycle increased significantly. This increase, after depositing the tenth cemented layer, was most pronounced during the testing period (the collected volume of water reached $34.578 \mathrm{~L}$ after the 33 rd wetting). This could be due to: (1) the expansion cracks at the tenth layer, which became, as cycles progressed, larger and more frequent; these cracks allowed higher water infiltration instead of being retained by the paste and (2) the network of cracks affected the tailings' stack below layer ten. However, the volume of water drained from the physical model seems to be more influenced by the "seasonal progression" of temperature and moisture conditions in the laboratory. Essentially, because the model was subjected to warmer and drier conditions during the winter, a more pronounced 
Fig. 4 Volume of leachate after each wetting/drying cycle (from the 1st to 34th cycles-the red line indicates the time of the cemented layer 10 addition)

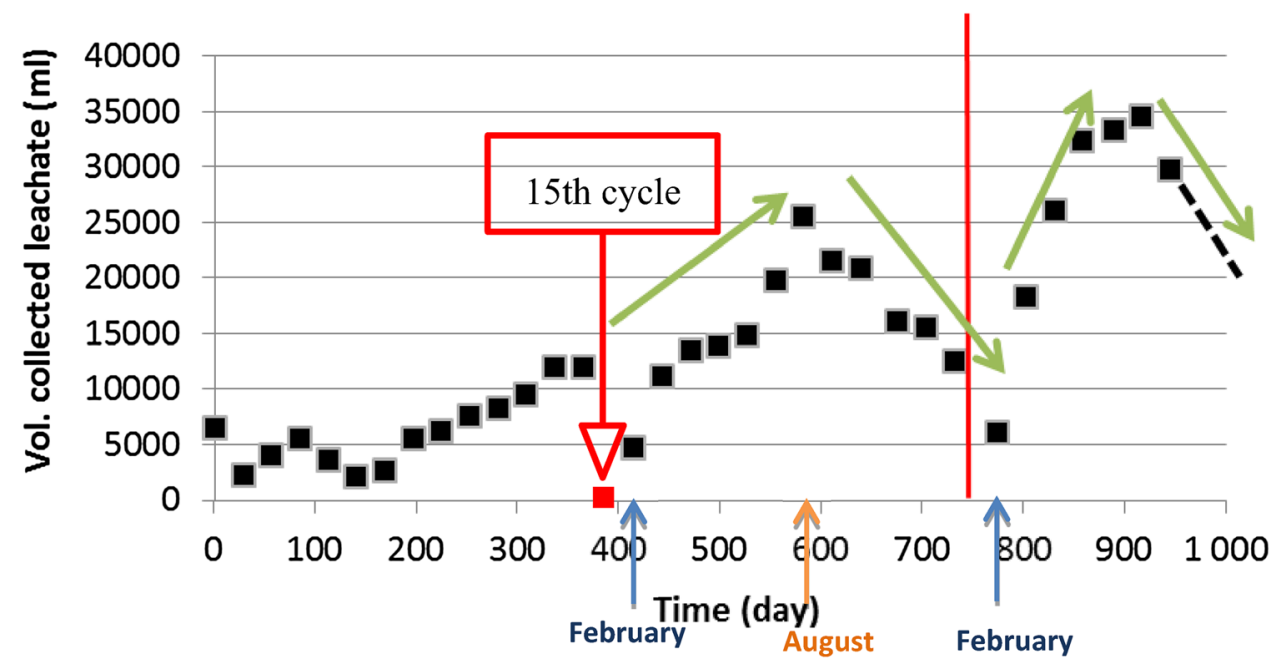

evaporation of water from the tailing stack was produced and less water drained in winter than in summer.

As a result of the introduction of the extended drying period during the 14th cycle, the tailings underwent a more pronounced desaturation compared to the average cycles. For comparison, the 18th cycle, where the volume of water drained at the bottom of the model was approximately the average volume of recovered water across all cycles (Fig. 4), was taken as a reference. Figure 5 and Tables 2 and 3 show the volumetric water content profiles in the different layers of tailings during two periods: immediately before the 15th wetting and immediately before the 18th wetting. Before the 15th wetting, the paste was desaturated; the volume of water in the physical model was approximately $24 \mathrm{~L}$ lower than the average value (18th cycle). This water volume decrease could potentially explain the tailings' desaturation and the absence of collected volume of water observed at the 15 th cycle.

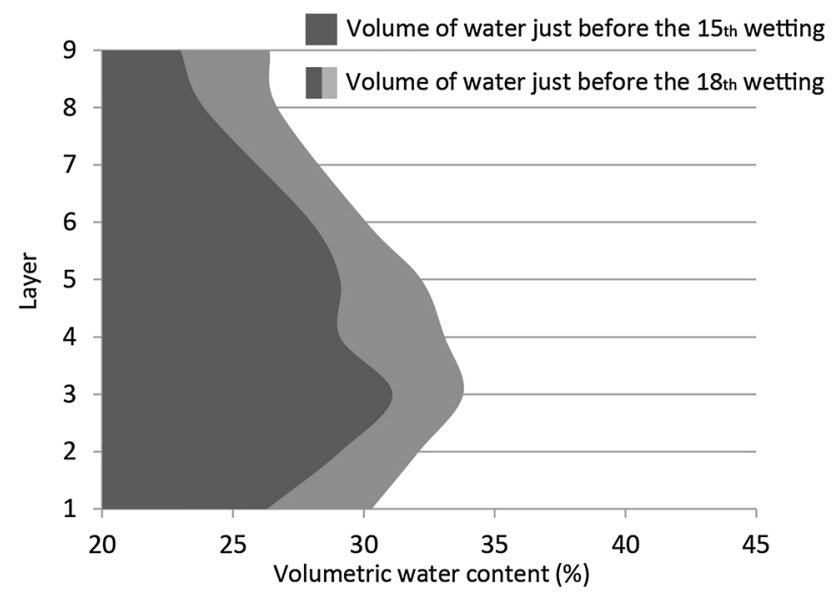

Fig. 5 Volume of water contained in the paste tailings in the physical model just before the 15 th wetting and just before the 18 th wetting

\section{Evolution of volumetric water content during wetting/drying profiles}

The evolutions of volumetric water content distribution obtained over the wetting/drying cycles are presented in Figs. 6 and 7. These figures present the volumetric water content profiles for the 5th, 14th, 18th, 26th, and 34th cycles.

Each figure is comprised of two graphs:

- Graph (a) shows the VWC profiles at three stages: (1) immediately before wetting (bold line), (2) at the end of the first day of wetting (thin solid line), and (3) at the end of the second day of wetting (dotted line).

- Graph (b) shows the VWC profiles during the drying period: (4) at the end of the second day of wetting (bold line), (5) 1 day after the end of wetting (thin solid line), (6) 3 days after the end of wetting (dashed line), (7) 10 days after the end of wetting (dotted line), and (8) at the end of the drying period (dashed-dotted lines).

During the testing period, the VWC of the three bottom layers of the physical model (i.e., layers 1, 2, and 3-see Figs. 6 and 7) did not increase significantly after the first wetting (water percolated more slowly due to time transfer). However, the VWC of the upper layers increased immediately after the first phase of wetting (from 28 to $34 \%$ for layer 9 and from 29 to $69 \%$ for layer 10) due to the infiltration of water. In contrast, the VWC of the lower layers did not change much at the beginning of the wetting period (water percolated more slowly similarly due to time transfer). In general, prior to the deposition of the tenth layer, the VWC increased at the top and at the bottom of the model after the second wetting, while after the deposition of the tenth cemented layer, changes in the VWC occurred mainly after the first day of wetting. The 
Table 2 Calculating volume of water contained in the tailings inside the physical model just before the 18th wetting

\begin{tabular}{|c|c|c|c|c|c|c|c|}
\hline Layer & $O_{\mathrm{w}}$ & $O_{\mathrm{a}}=n-O_{\mathrm{w}}$ & $V_{\mathrm{a}}=O_{\mathrm{a}} \times V_{\mathrm{t}} / 100$ & $\begin{array}{l}e=(n / 100) / \\
(1-(n / 100))\end{array}$ & $V_{\mathrm{v}}=n \times V_{\mathrm{t}} / 100$ & $V_{\mathrm{s}}=V_{\mathrm{v}} / e$ & $V_{\mathrm{w}}=V_{\mathrm{t}}-V_{\mathrm{s}}-V_{\mathrm{a}}$ \\
\hline 1 & 26.30 & 18.9 & 7.56 & 0.82 & 18.08 & 21.92 & 10.52 \\
\hline 2 & 29.10 & 16.1 & 6.44 & 0.82 & 18.08 & 21.92 & 11.64 \\
\hline 3 & 31.10 & 4.6 & 1.84 & 0.56 & 14.28 & 25.72 & 12.44 \\
\hline 4 & 29.10 & 6.6 & 2.64 & 0.56 & 14.28 & 25.72 & 11.64 \\
\hline 5 & 29.10 & 6.6 & 2.64 & 0.56 & 14.28 & 25.72 & 11.64 \\
\hline 6 & 28.00 & 7.7 & 3.08 & 0.56 & 14.28 & 25.72 & 11.20 \\
\hline 7 & 25.95 & 11.8 & 4.72 & 0.56 & 14.28 & 25.72 & 9.56 \\
\hline 8 & 23.90 & 12.7 & 5.08 & 0.56 & 14.28 & 25.72 & 9.20 \\
\hline 9 & 23.00 & 35.7 & 14.28 & 0.56 & 14.28 & 25.72 & 0 \\
\hline Total & & & 48.28 & & 136.12 & 223.88 & $87.84 \mathrm{~L}$ \\
\hline
\end{tabular}

$O_{\mathrm{w}}$ volumetric water content $(\%), O_{a}$ volumetric air content $(\%), n$ total porosity $(\%), V_{t}$ total volume $(\mathrm{L}), V_{s}$ volume of solid (L), $V_{v}$ void volume (L), $V_{a}$ air volume (L), $V_{w}=$ volume of water $(\mathrm{L}), e$ void ratio

Table 3 Calculating volume of water contained in the tailings inside the physical model just before the 18th wetting

\begin{tabular}{|c|c|c|c|c|c|c|c|}
\hline Layer & $O_{\mathrm{w}}$ & $O_{\mathrm{a}}=n-O_{\mathrm{w}}$ & $V_{\mathrm{a}}=O_{\mathrm{a}} \times V_{\mathrm{t}} / 100$ & $\begin{array}{l}e=(n / 100) / \\
(1-(n / 100))\end{array}$ & $V_{\mathrm{v}}=n \times V_{\mathrm{t}} / 100$ & $V_{\mathrm{s}}=V_{\mathrm{v}} / e$ & $V_{\mathrm{w}}=V_{\mathrm{t}}-V_{\mathrm{s}}-V_{\mathrm{a}}$ \\
\hline 1 & 30.30 & 14.90 & 5.96 & 0.82 & 18.08 & 21.92 & 12.12 \\
\hline 2 & 32.10 & 13.10 & 5.24 & 0.82 & 18.08 & 21.92 & 12.84 \\
\hline 3 & 33.80 & 3.60 & 1.44 & 0.56 & 14.28 & 25.72 & 12.84 \\
\hline 4 & 33.10 & 1.90 & 0.76 & 0.56 & 14.28 & 25.72 & 13.52 \\
\hline 5 & 32.20 & 2.60 & 1.04 & 0.56 & 14.28 & 25.72 & 13.24 \\
\hline 6 & 30.10 & 3.50 & 1.40 & 0.56 & 14.28 & 25.72 & 12.88 \\
\hline 7 & 28.20 & 7.50 & 3.00 & 0.56 & 14.28 & 25.72 & 11.28 \\
\hline 8 & 26.70 & 5.60 & 2.24 & 0.56 & 14.28 & 25.72 & 12.04 \\
\hline 9 & 26.40 & 9.00 & 3.60 & 0.56 & 14.28 & 25.72 & 10.68 \\
\hline Total & & & 24.68 & & 136.12 & 223.88 & 111.44L \\
\hline
\end{tabular}

$O_{w}$ volumetric water content $(\%), O_{a}$ volumetric air content $(\%), n$ total porosity $(\%), V_{t}$ total volume (L), $V_{s}$ volume of solid (L), $V_{v}$ void volume $(\mathrm{L}), V_{a}$ air volume $(\mathrm{L}), V_{w}$ volume of water $(\mathrm{L}, e$ void ratio

maximum (saturated) water contents changed significantly throughout the testing period, indicating the dynamic behavior of the tailings' stack; however, in most cases, this saturation occurred during the end of the second wetting day for the upper layers and 1 day after the second wetting day for the lower layers (the slow percolation of water effect).

From the 15th to 26th cycles, the VWC increased from one cycle to another at the end of each wetting period; i.e., from 34 to $37.5 \%$ for layer 9 and from 36 to $42 \%$ for layer 5. This increase in VWC indicates a trend towards water storage; however, for the layers located at the bottom of the physical model (layers 1, 2, and 3), the VWC did not change significantly after the end of the first day of each wetting cycle. This could be explained by slow percolation of water during the wetting, which was corroborated by visual observations. An accumulation of water on the physical model's surface layer was observed during the wetting period; this persisted until the third day after the first wetting, and appeared to increase considerably with each cycle.

During each drying period, the VWC gradually evolved to a lower volumetric water content at the end. This decrease is expressed particularly in the upper layers, especially the 9th layer (the VWC at the end of the drying period down by around $6 \%$ ), which was more affected by evaporation, water distribution, and desiccation due to direct contact with the atmosphere.

Deposition of the tenth layer had an important impact on the stack's hydrogeological behavior. After the addition of the tenth layer, which was cemented, the VWC profiles of the underlying layers became increasingly similar, indicating slower paste saturation and desaturation during wetting/drying cycles. In other words, the deposition of the cemented surface layer resulted in a progressive increase in VWC, as a result of increased retention of water, as the cycles progressed. This phenomenon was especially 
Fig. 6 Volumetric water content profiles during the wetting/drying cycles 5,14 , and 18: a during the wetting phases and $\mathbf{b}$ during the drying phases: (1) before wetting (bold line), (2) at the end of the first wetting (thin line), (3) at the end of the second wetting (dashed line), (4) at the end of second wetting (bold line), (5) a day after the second wetting (thin line), (6) 3 days after the second wetting (dashed line), (7) 10 days after the second wetting (dashed line), and (8) at the end of the period of drying, after 30 days (line dot dash). The red arrows represent the direction of the volumetric water content evolution a

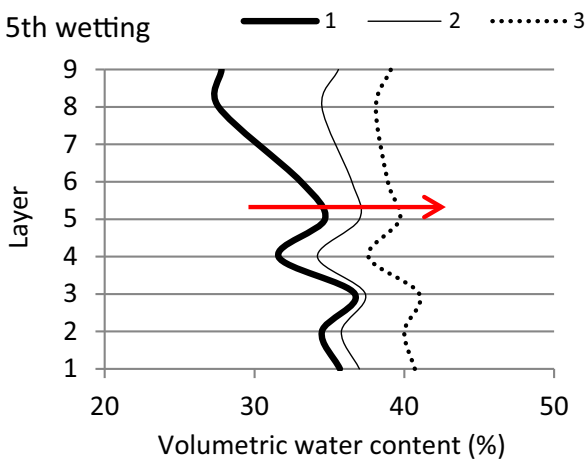

14th wetting $\longrightarrow 1 \longrightarrow 2 \quad \cdots \cdots . . .3$
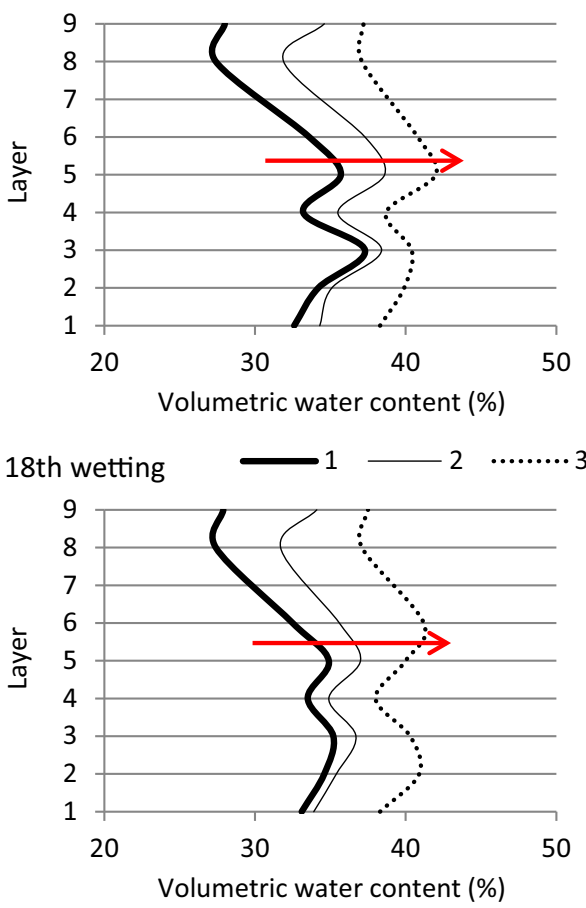

b
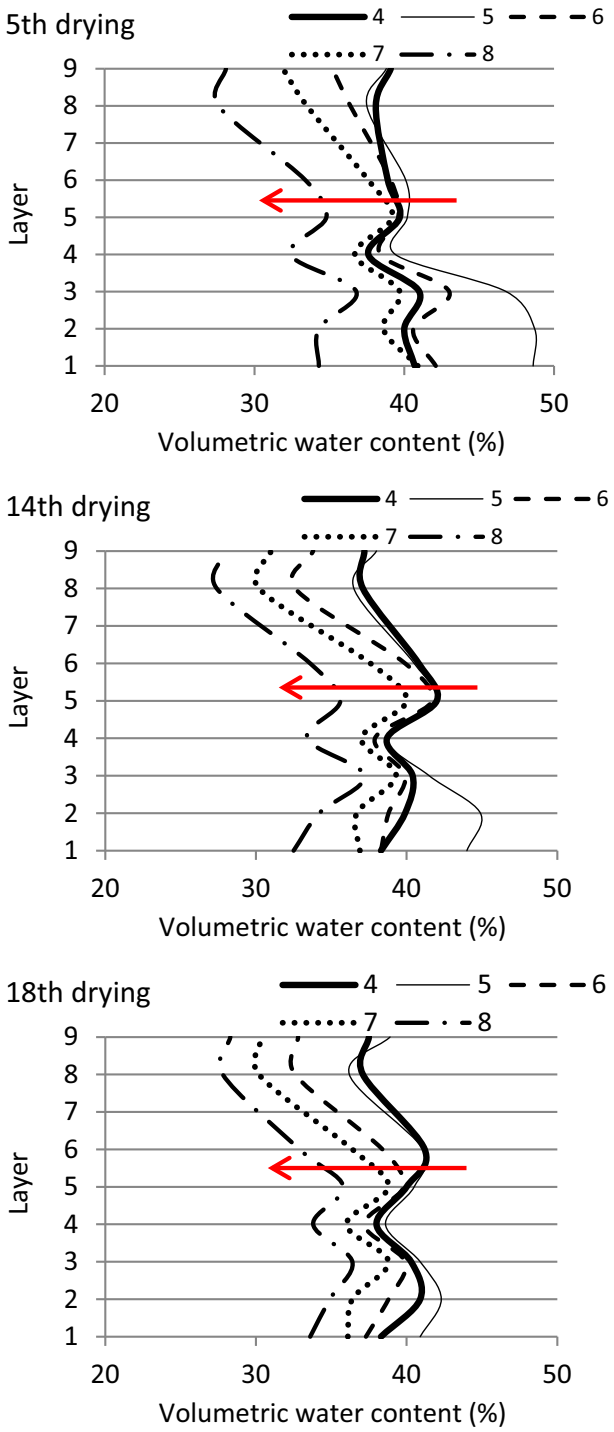

notable in the uncemented layers, which could be explained by a gradual saturation of the stack after the addition of the tenth layer. The cemented layer deposited on the top of the physical model seems to play a role in protecting underlying layers against evaporation.

During the wetting period, and a day after the second rinse, the VWC of the tenth cemented layer was at its highest. The VWC of the tenth layer increased immediately after the first wetting and reached a value of up to $69 \%$. This VWC decrease after the first wetting day downs up to about $30 \%$. This may be due to the development of a network of cracks on the surface of layer 10, which increased the rate of drainage at this layer. Following the second wetting, the VWC of the tenth layer increased rapidly to values between 53 and $66 \%$; this value generally persisted until the second day after the first wetting
(39-59 \%). This was corroborated with visual observations, as there was the accumulation of water on the surface of the physical model during the wetting period which disappeared on the first day after each rinse. The tenth layer became dry except for the major fractures (preferential paths for water infiltration) affecting it. Throughout the drying period, the VWC of the tenth layer remained almost constant (approximately $30 \%$ ).

\section{Volumetric water content (and the estimated degree of saturation) evolution of tree different layers of the stack}

Figures 8, 9, 10 show the evolution of the VWC (and the estimated degree of saturation) during the wetting/drying cycles $(5,14,18,26$, and 33) on the topmost uncemented 
Fig. 7 Volumetric water content profiles during the wetting/drying cycles 26 and 34: a during the wetting phases and $\mathbf{b}$ during the drying phases: (1) before wetting (bold line), (2) at the end of the first wetting (thin line), (3) at the end of the second wetting (dashed line), (4) at the end of second wetting (bold line), (5) a day after the second wetting (thin line), (6) 3 days after the second wetting (dashed line), (7) 10 days after the second wetting (dashed line), and (8) at the end of the period of drying, after 30 days (line dot dash). The red arrows represent the direction of the volumetric water content evolution

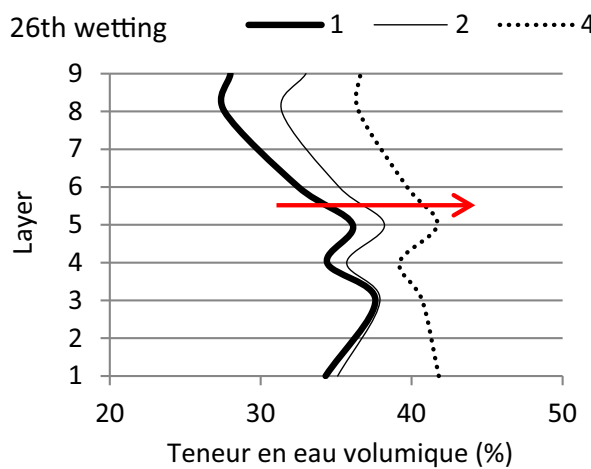

34th wetting $\quad 1 \quad 2 \quad \cdots \cdots \cdots$

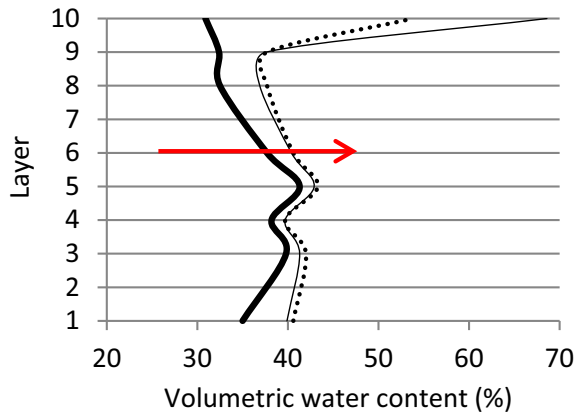

b
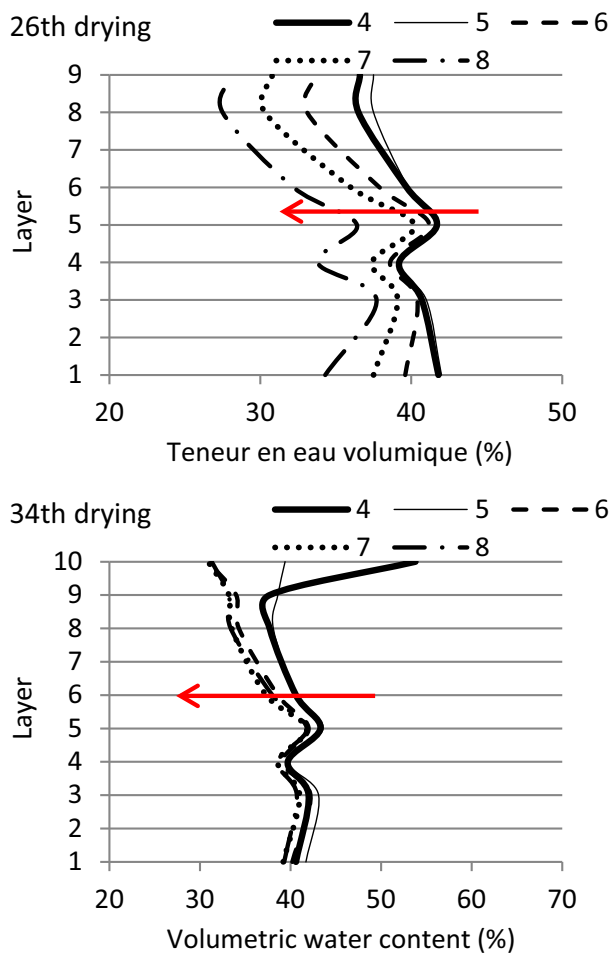

Fig. 8 Evolution of the volumetric water content and the estimated degree of saturation in layers 9 (top), during the cycles $5,14,18,26$, and 33 (respectively, C5, C14, $\mathrm{C} 18, \mathrm{C} 26$, and $\mathrm{C} 33$ )

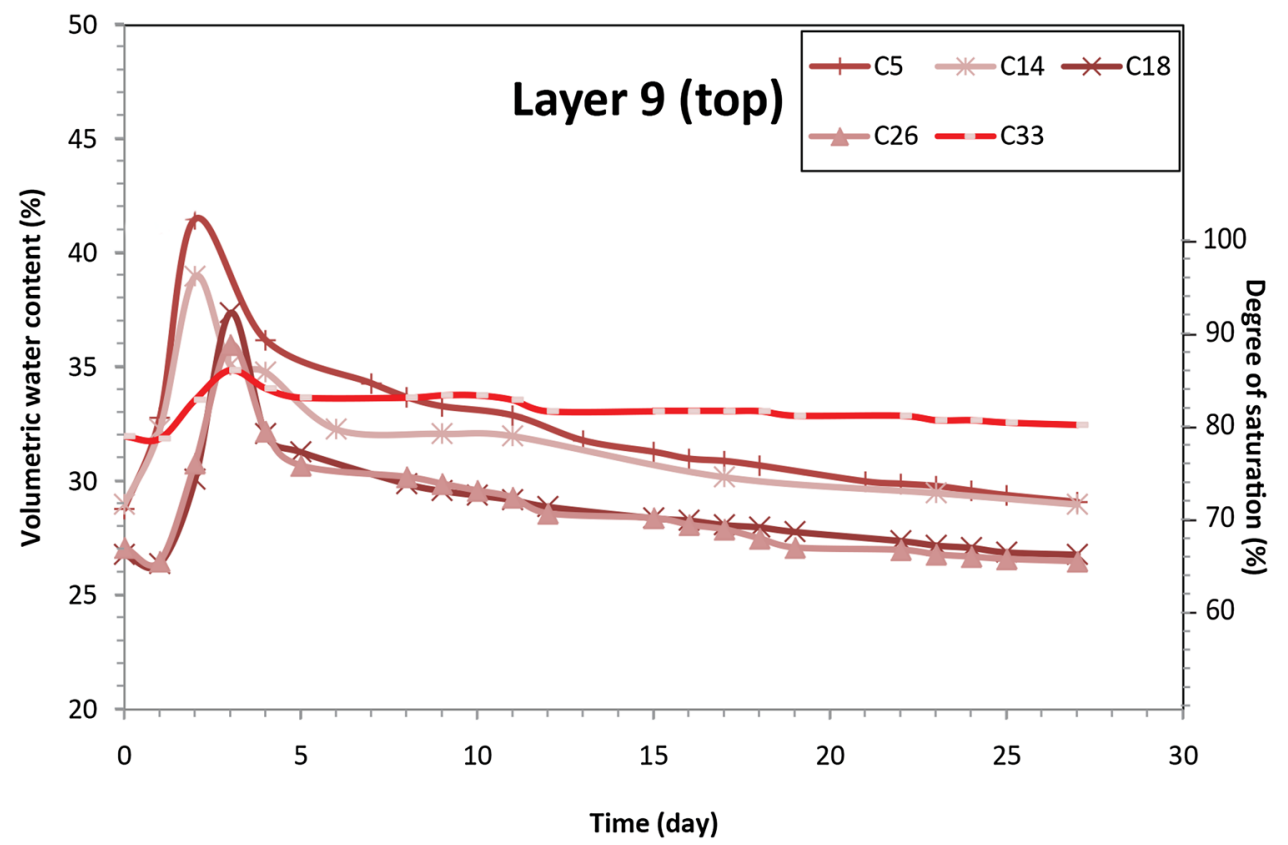

layer (9), the middle uncemented layer (5), and basal cemented layer. During the period following the deposition of the tenth layer, layers 1 and 9 showed a rapid increase in volumetric water content, as compared to layer 5, during wetting. During the drying periods, the evolution of the VWC changed from one layer to another. For layer 9, the
VWC decreased greatly during the first 7-8 days of each wetting/drying cycle, while in the middle layer (5), a significant decrease in VWC was more pronounced during the first 4-5 days of each cycle.

At the end of cycles 1-27, the VWC of layer 9 was lower: values ranged between 30 and $32 \%$, which 
Fig. 9 Evolution of the volumetric water content, and the estimated degree of saturation, in layers 5 (middle), during the cycles $5,14,18,26$, and 33 (respectively, C5, C14, $\mathrm{C} 18, \mathrm{C} 26$, and C33)

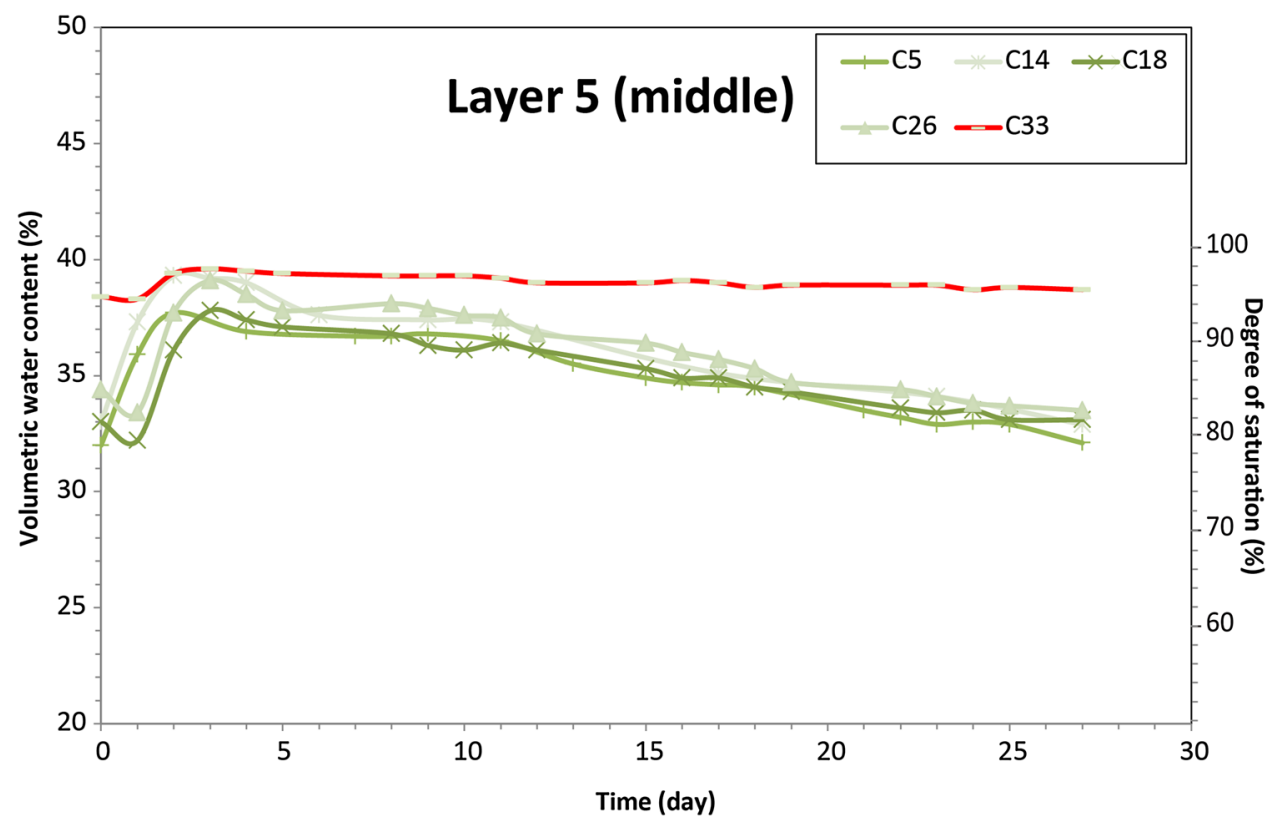

Fig. 10 Evolution of the volumetric water content, and the estimated degree of saturation, in layers 1 (bottom, cemented), during the cycles 5 , 14, 18, 26, and 33 (respectively, C5, C14, C18, C26, and C33)

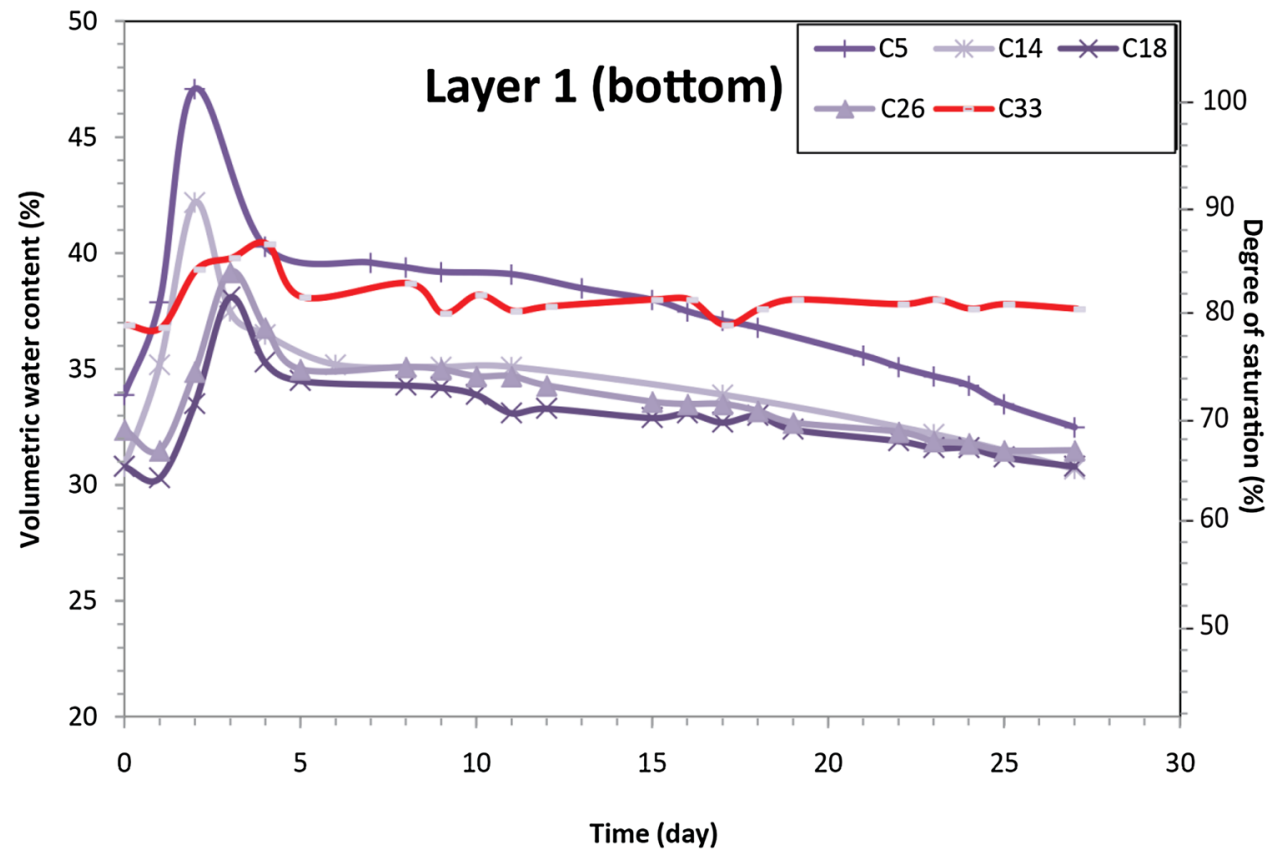

corresponds to an approximate degree of saturation between 74 and $79 \%$. Over the same period, in layer 1, the VWC was between 32 and $41 \%$, which corresponds to an approximate degree of saturation between 68 and $87 \%$. At layer 5, the VWC was between 36 and $41 \%$ for the same period, which corresponds to an approximate degree of saturation between 88 and $100 \%$.

Following the deposition of the tenth cemented layer at the top of the stack, the evolution of the VWC of the tailings showed a gradual desaturation of the paste compared to the previous cycles. Layer 9 rapidly increased in VWC during the wetting periods (Fig. 8). The increase in VWC was in the same range for layer 1 over the same period, but it was less pronounced for layer 5. This difference could be explained by: (1) the slow percolation of water to layers in the middle and at the bottom of the model due to compaction which would reduce the expression of cracks and (2) the dissolution of cement and formation of cracks in layer 1 . These later are the main pathways allowing deeper layers to desaturate. 
In layers 1 and 9, the VWC decreased rapidly during the first 5 days of a wetting/drying cycle, followed by a nearly linear decrease. In the middle layer (5), the VWC decreased linearly along cycles with a certain delay compared to the tenth layers. This behavior could relate to the progressive desaturation and water supply from the upper layers. At the end of cycles 28-33, the VWC of layer 9 was between 31 and $33 \%$, which corresponds to an approximate degree of saturation between 76 and $81 \%$. Over the same period, in layer 1, the VWC was between 36 and $39 \%$ (corresponding to an approximate degree of saturation between 76 and $83 \%$ ). The VWC of layer 5 was the high with values between 38 and $42 \%$, corresponding to an approximate degree of saturation between 95 and $102 \%$, which does not represent an optimal interval for the reactivity of sulphides according to Gosselin et al. [19], Hamdi [20], and Bouzahzah [12].

The evolution of the VWC of layer 1 was much the same at layer 9 . This is mainly due to the drainage at the bottom of the model and to the water distribution in layer 9 . In fact, in the field conditions, the evolution of the VWC of the first layer will be closer to that of layer 5. Similar behavior was observed in the field within the experimental cell tests [7]

\section{Surface observations (layers 9 and 10)}

Monitoring of the surface of layer 9 at the end of each drying period from the 15th-27th cycles did not reveal the manifestation of significant cracks except at the end of the 19th drying period when several cracks appeared on one side of the surface. Immediately after the end of the wetting periods, these cracks reopened in the same locations.

The surface of layer 9 became increasingly rustcoloured with the progression of the wetting/drying cycles. This may have been due to the oxidation of the paste tailings at the surface and the precipitation of iron given that the $\mathrm{pH}$ of the leachates remained near neutral throughout the experiments.

Figure 11 shows the surface cemented layer (layer 10) from the time of its deposition through the next $6 \mathrm{~h}$. These photographs illustrate the development of the main cracks just $6 \mathrm{~h}$ after the tenth layer's deposition. The formation of the cracks appears to be related to the thickness of the layer (about $4 \mathrm{~cm}$ ), which will subsequently impact on: (a) the rate of infiltration of the rinse water in the tenth layer, (b) the volumetric water content in all layers, (c) the oxygen diffusion, and (d) the acid generation potential of the material.

The cracks affecting layer 10 (some of which have a depth of $4 \mathrm{~cm}$, i.e., the full thickness of the layer) closed partly during wetting and reopened in the same locations during drying periods. They seem to control the VWC and water infiltration of the layer.

\section{Discussion}

Testing was performed for 34 cycles after which the model was dismantled to collect paste specimens; this section focuses on the characterization of the paste samples. The collected "leached" samples were characterized, and the results were compared to those obtained for reference (unleached) samples. The paste microstructure was characterized by MIP and SEM coupled with EDS microanalysis.

\section{Procedures for the dismantling of the model and key observations}

Prior to sampling, it was important to evaluate the location of the layer interfaces; however, the interfaces between the
Fig. 11 Photo of the surface of the tenth cemented layer: a just after its deposition and b $6 \mathrm{~h}$ after its deposition

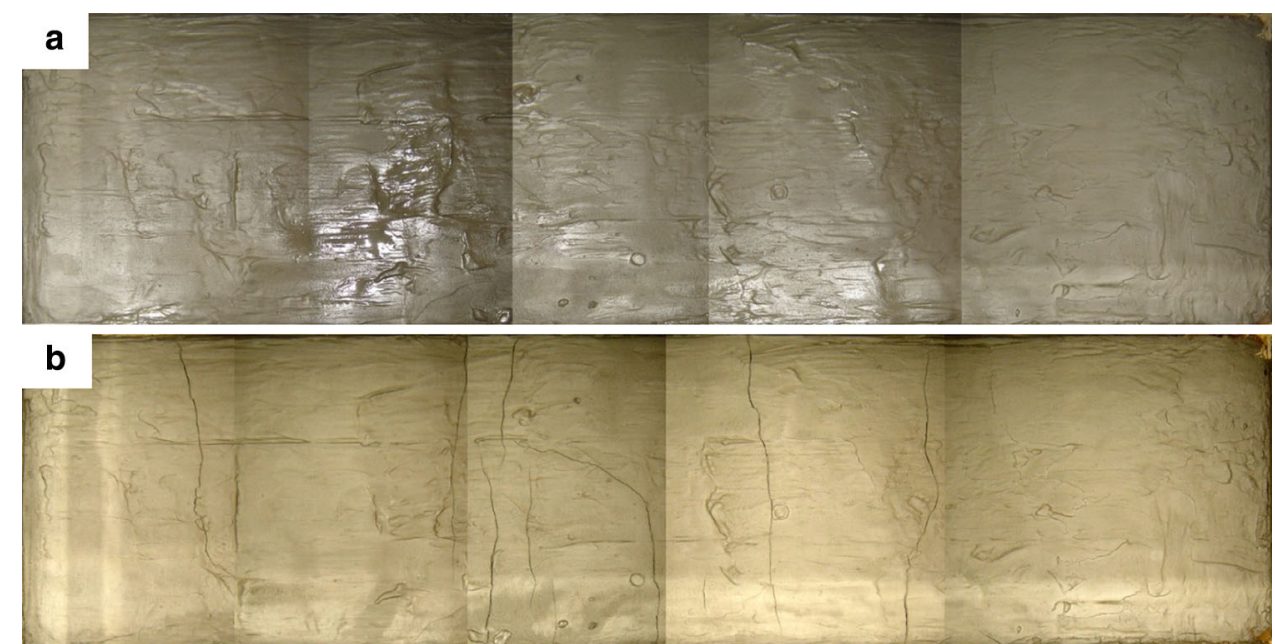



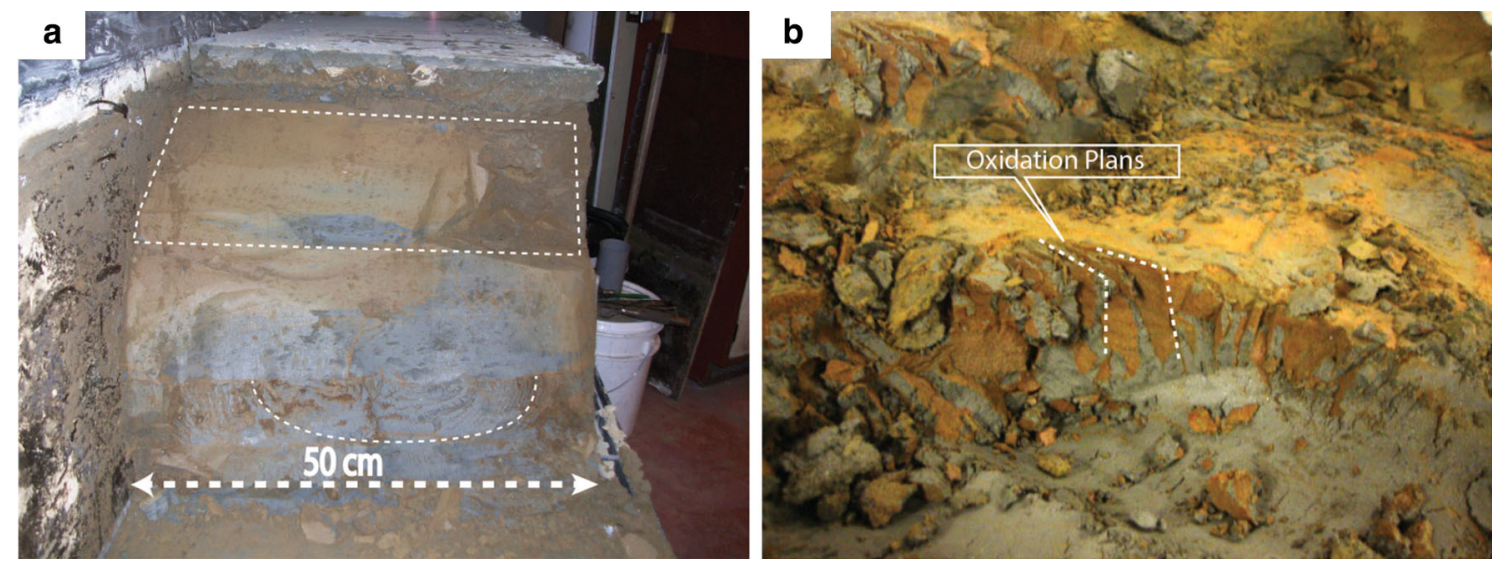

Fig. 12 Photographs of a aggregate oxidation in the uncemented upper layers, and oxidation according to a preferential pathway for the central and the lower layers and $\mathbf{b}$ of the layer 2 preferential oxidation pathway

paste layers were not clearly visible (Fig. 12a), except for interfaces between cemented and uncemented layers by the fact that the layer 10 was more recent than layer 9; thus, it had good physical integrity and it was easily distinguishable from layer 9 by its color and its rigidity. Layer 10 was characterized by its grey and less-oxidized colour, as well as its hard and rigid character very distinct from the rest of the layers in the model.

Macroscopic analysis of the uncemented layers 7, 8, and 9 showed the bulk oxidation and friability of these layers; these features became less intense towards the base of the model. In the middle layers (i.e., 4,5 , and 6 ), the oxidation was less pronounced and followed vertical preferential pathways. During dismantling, it was observed that the uncemented layers $3,4,5$, and 6 were harder and more resistant; the physical integrity was generally good in these layers as compared to the upper uncemented layers (i.e., 7, 8 and 9). Visual examination of the third uncemented layer showed similarities with the second cemented layer in terms of rigidity, aspect, and the extent of oxidation.

Macroscopic observations of layers 1 and 2 (Fig. 12b) revealed vertical preferential pathways, where oxidation could occur. This effect is likely related to shrinkage caused by cement hydration and self-desiccation (for more details, see $[17,33]$. The oxidation was more pronounced in the bottom layer. The physical integrity of layer 2 was good compared to layer 1 (see Fig. 13).

\section{Microstructural characteristics}

Table 4 presents data on the total porosity and the threshold diameters determined by MIP; samples were taken from cemented layers and several of the uncemented layers, coring, and reference pastes (i.e., unleached samples, both cemented and uncemented). After dismantling the physical model, the values of these parameters had changed. The threshold diameter of cemented paste samples differed according to the place, where they had been collected. The sample corresponding to layer 1 had a threshold diameter similar to that of the reference sample $(3.5 \mu \mathrm{m}$ for layer 1 and $3.3 \mu \mathrm{m}$ for the unleached sample), while the threshold diameter of the two other cemented layers was lower than the unleached tailings $(2.8 \mu \mathrm{m}$ for layer 2 and $1.35 \mu \mathrm{m}$ for layer 10). The total porosity was $39 \%$ for layers 2 and 10 and approximately $35 \%$ for layer 1 , which was lower than the cemented unleached tailings (47\%).

Regarding uncemented layers, the value of threshold diameter was lower in the samples collected from layer 5 $(2 \mu \mathrm{m})$ and from layer $3(1.7 \mu \mathrm{m})$ than in the unleached samples. The total porosity was lower in the sample from layer $5(34 \%)$ than in the unleached tailings $(40.3 \%)$; total porosity was only slightly less in the sample collected from layer $3(39 \%)$ than the unleached tailings. The change in the microstructure could be explained by a slight deterioration of the cementitious matrix in the collected samples.

The long-term evolution of the threshold diameter and total porosity measured by MIP in layer 1 (cemented) implies a change in the microstructure of paste, which is corroborated by the results of the VWC evolution (Sects. 3.1 and 3.5). Immediately after the wetting period, the VWC of layer 1 decreased quickly until it began a more gradual decrease. During this last phase of the drying period, the shape of the slope decrease changed with the cycle's progression.

The evolution of the threshold diameter during different periods of the test in the cemented layers $(3.3 \mu \mathrm{m}$ for the initial rejection, $3.8 \mu \mathrm{m}$ after coring, and, after dismantling: $3.5 \mu \mathrm{m}$ for layer $1,2.8 \mu \mathrm{m}$ for layer 2 , and $1.35 \mu \mathrm{m}$ layer 10) revealed a destruction of the cementious matrix. However, data collected by ICP-AES on the leachate samples did not display a significant loss of calcium, which 
Fig. 13 Sketch of paste layers in the physical model, summarizing visual observations (adapted from Deschamps et al. [15])

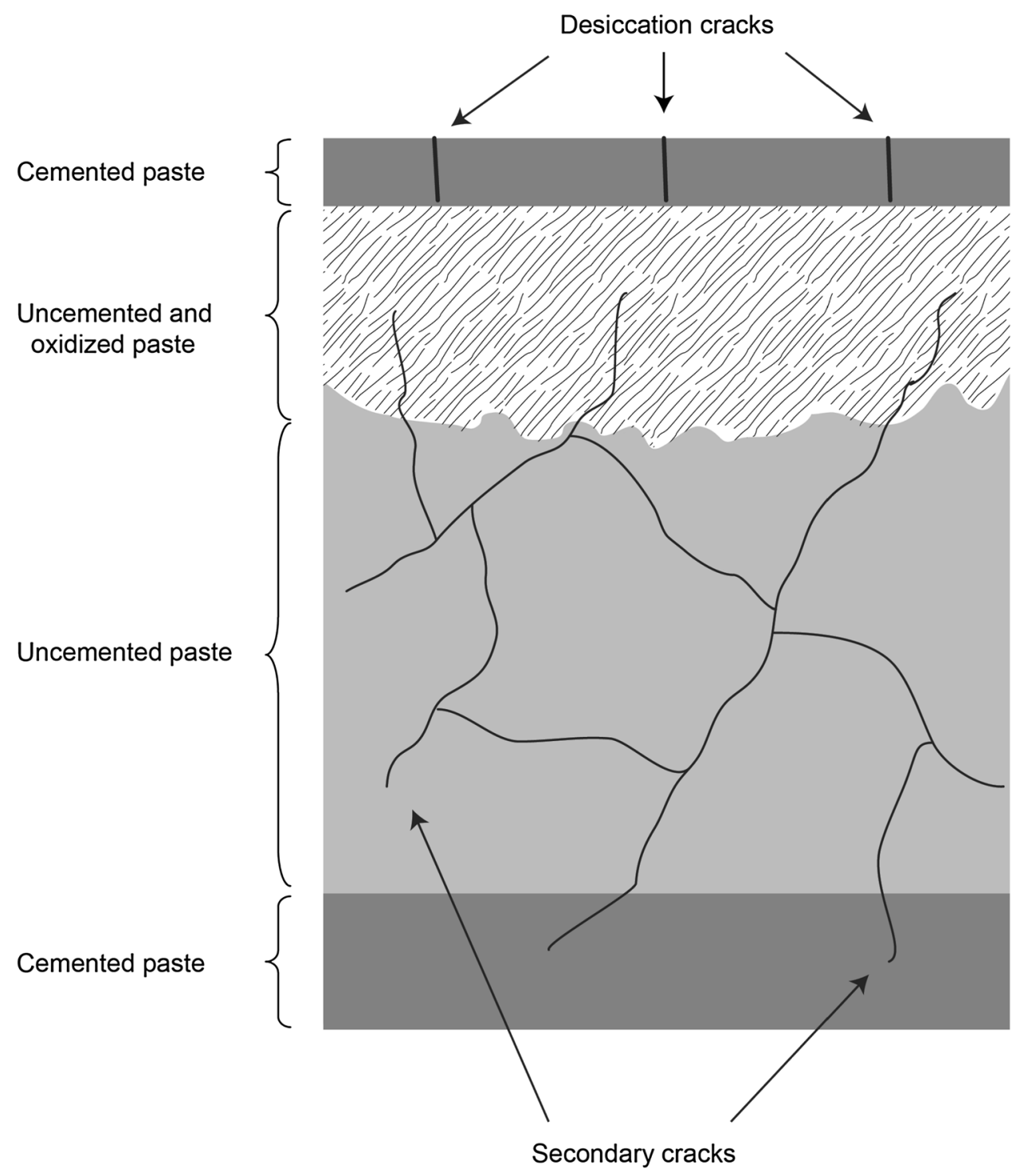

Table 4 Main microstructural characteristics of the cemented paste and the uncemented unleached samples (ref), for samples taken after coring [14] and for those collected after dismantling

\begin{tabular}{|c|c|c|c|c|c|c|c|c|c|}
\hline & \multicolumn{5}{|c|}{ Cemented } & \multicolumn{4}{|c|}{ Uncemented } \\
\hline & $\begin{array}{l}\text { Layer } \\
1\end{array}$ & $\begin{array}{l}\text { Layer } \\
2\end{array}$ & $\begin{array}{l}\text { Layer } \\
10\end{array}$ & $\begin{array}{l}\text { After } \\
\text { coring }\end{array}$ & $\begin{array}{l}\text { Unleached } \\
\text { tailings }\end{array}$ & $\begin{array}{l}\text { Layer } \\
3\end{array}$ & $\begin{array}{l}\text { Layer } \\
5\end{array}$ & $\begin{array}{l}\text { After coring } \\
\text { (layer 5) }\end{array}$ & $\begin{array}{l}\text { Unleached } \\
\text { tailings }\end{array}$ \\
\hline Total porosity MIP (\%) & 34.9 & 38.6 & 39 & 45.2 & 46.6 & 39 & 33.7 & 35.7 & 40.3 \\
\hline Threshold diameter $(\mu \mathrm{m})$ & 3.5 & 2.8 & 1.3 & 3.8 & 3.3 & 1.7 & 2 & 2.3 & 4.1 \\
\hline
\end{tabular}

could imply a loss of cement. Instead, the change in threshold diameter was likely due to a dissolution of cement hydrates and precipitation of other more stable phases.

SEM images obtained from samples collected from various locations in the physical model (cemented layers, uncemented layers, and a few discontinuities) revealed a precipitation of secondary minerals (principally iron hydroxides and gypsum) on the surface of mineral grains or filling the interstices, as shown in Figs. 14 and 15. SEM images and the change in the threshold diameter values throughout the period of the test indicate a partial destruction of the cementious matrix. This could result in an increase in the rate of water drainage (Sect. 3.1). 

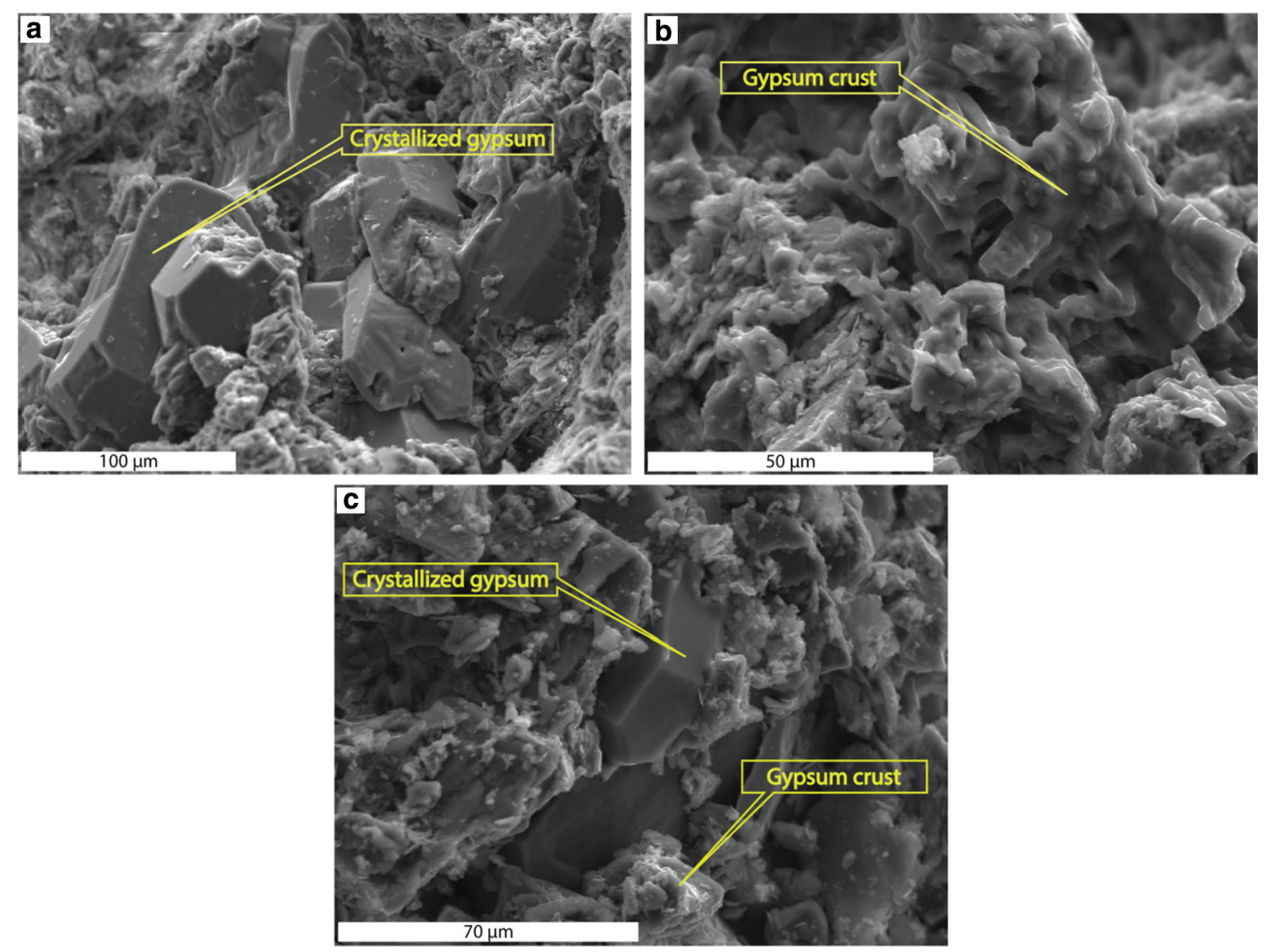

Fig. 14 SEM images of weathered crack zones in uncemented fourth layer: a crystallized gypsum and $\mathbf{b}$ gypsum crust
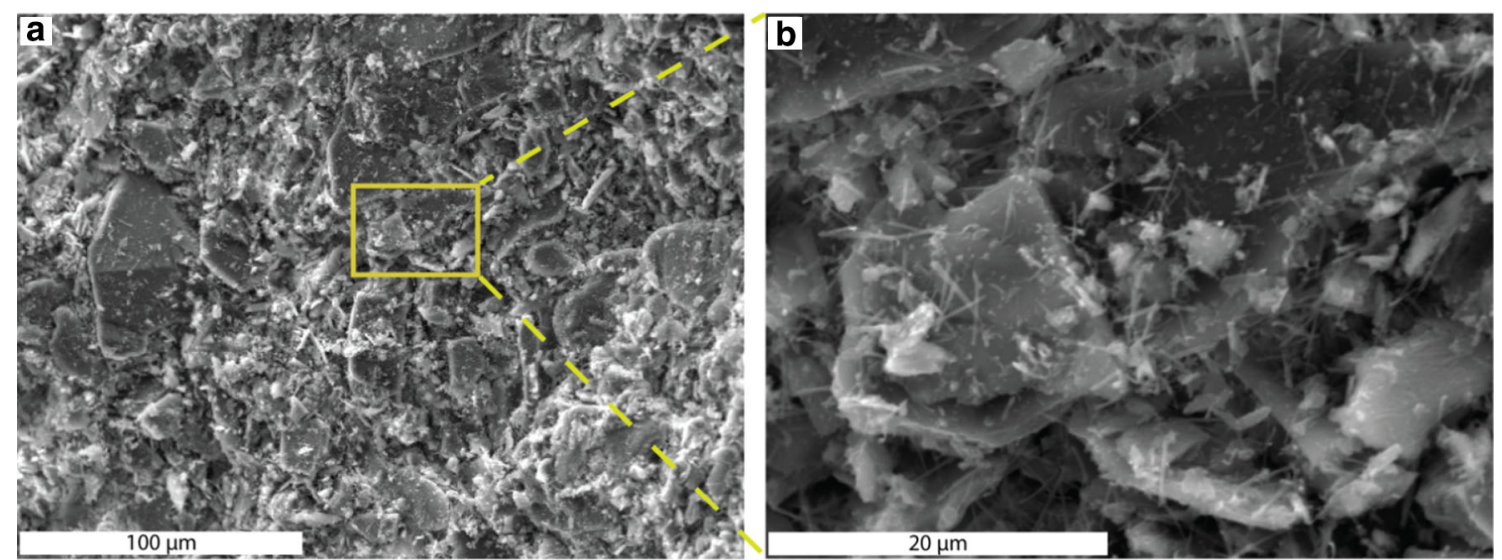

Fig. 15 SEM images of a crystallized gypsum and $\mathbf{b}$ is a magnification of $\mathbf{a}$

\section{Main conclusions}

This paper focuses on a laboratory study of the long-term environmental behavior of sulphidic paste tailings deposited using the SPD technique, as well as the cement amendment used to the control AMD production. To achieve this, an instrumented physical model was monitored over the course of 34 cycles of wetting and drying. This model was filled initially with nine layers of paste tailings; only the first two lower layers of which were cemented with $2 \%$ w/w Portland cement (PC10). The tailings were subjected to wetting/drying cycles every 4 weeks with $40 \mathrm{~L}$ of tap water. The study was divided into six stages: (1) depositing the pastes, (2) wetting/drying 
cycles of the pastes, (3) coring and analysis of samples after the tenth wetting cycle, (4) long-term monitoring of the SPD stack (from the 10th to 27th cycles), (5) depositing a tenth paste layer (cemented with $2 \%$ w/w of Portland cement) at the end of the 27th drying cycle, (6) dismantling the physical model in the middle of the 34th drying cycle and the analysis of samples through a multifaceted characterization. The first three stages of this work were performed by Deschamps [14].

The main results of this work are summarized as follows:

- The volume of collected leachate at the bottom of the physical model showed variations throughout the testing period. These increases and decreases could be potentially be attributed to the effect of the expanding cracks, or changes in the temperature and moisture conditions in the laboratory across seasonal cycles.

- The topmost cemented layer (10) appears to play a role in protecting the underlying layers against evaporation. Following its deposition, the tailings' stack then had a slower desaturation compared to the previous cycles.

- The desiccation cracks formed on the surface of layer 10 appeared to result in a rapid desaturation, as well as the oxidation of sulphidic tailings following the diffusion of oxygen.

- SEM and MIP analyses on solid samples from the model show that the cemented matrix experienced a partial dissolution, which allowed for the expression of a porosity that was subsequently, in large part, a space for the precipitation of secondary minerals, such as iron hydroxides and gypsum.

Acknowledgments The authors would like to thank the Canada Research Chair on Integrated Management of Sulfidic Wastes using Backfill for their financial support. The authors also would like to acknowledge the URSTM-UQAT laboratories.

\section{References}

1. Bascetin A, Taylu S, Adiguzel D, Ozdemir O (2016) New technologies on mine process tailings disposal. J Geol Resour Eng. 2:63-72

2. Bascetin A, Tuylu S, Adiguzel D, Akkaya U, Binen IS (2013) Investigation of suitability of $\mathrm{Pb}-\mathrm{Zn}$ mine tailings for surface paste disposal. 23rd world mining congress, Montreal, CANADA, August 11-15, 301

3. Alakangas L, Dagli D, Sven Knutsson S (2013) Literature review on potential geochemical and geotechnical effects of adopting paste technology under cold climate conditions. Report Luleå University of Technology, p 36

4. ASTM C 143-00 (2002) Standard test method for slump of hydraulic cement concrete. In 2002 Annual Book of ASTM Standards. American Society for Testing and Materials (ASTM), Philadelphia, PA
5. Aubertin M, Bussière B, Bernier L (2002) Environnement et gestion des rejets miniers-Manual on CD-ROM, Les Presses internationales Polytechnique, Montréal

6. Azam SH, Li Q (2010) Tailings dam failure: a review of the last hundred years. Geotech News 28(4):50-54

7. Barast G, Benzaazoua M, Maqsoud A, Bussière B (2014) Long term hydro-geochemical behaviour of surface paste disposal in field experimental cells. In: Proceedings of the Conference Canadienne de Géotechnique, GeoRegina, CD-Rom

8. Benzaazoua M, Kongolo M (2003) Physico-chemical properties of tailing slurries during environmental desulphurization by froth flotation. Int J Miner Process 66:221-234

9. Benzaazoua M, Belem T, Jollette D (2000) Investigation de la stabilité chimique et son impact sur la qualité des remblais miniers cimentés Études et recherches/Rapport R-260. IRSST, Montréal, p 157

10. Benzaazoua M, Ouellet J, Servant S, Newman P, Verburg RBM (1999) Cementitious backfill with hight sulfur content: physical, chemical and mineralogical characterization. Cem Concr Res 29:719-725

11. Benzaazoua M, Perez P, Belem T, Fall M (2004) A laboratory study of the behaviour of surface paste disposal. In: Proceedings of the 8th Minefill 2004 sympodium, Beijing, China, pp 180-192

12. Bouzahzah H (2013) Modification et amélioration des tests statiques et cinétiques pour une prédiction fiable du drainage minier acide. Thèse de doctorat en sciences de l'environnement, Université du Québec en Abitibi-Témiscamingue

13. Bussière B (2007) Colloquium 2004: hydro-geotechnical properties of hard rock tailings from metal mines and emerging geoenvironmental disposal approaches. Can Geotech J 44:1019-1052

14. Deschamps T (2009) Étude du comportement physique et géochimique d'un dépôt de résidus miniers en pâte dans des conditions de surface. (Ph.D.), Université du Québec en AbitibiTémiscamingue

15. Deschamps T, Benzaazoua M, Bussière B, Aubertin M (2011) Laboratory study of surface paste disposal for sulfidic tailings: Physical model testing. Miner Eng 24(8):794-806

16. Fourie A (2012) Paste and thickened tailings: has the promise been fulfilled? GeoCongress 2012:4126-4135. doi:10.1061/ 9780784412121.424

17. Galaa, A, Grabinsky, A and Bawden, W (2012) Characterizing stiffness development in early age cemented paste backfills with sand in a non-destructive triaxial test. Canadian Geotechnical Conference, GeoManitoba

18. Gomez HI, Mayes WM, Rogerson M, Stewart DI, Burke IT (2016) Alkaline residues and the environment: a review of impacts, management practices and opportunities. J Clean Prod 112:3571-3582

19. Gosselin M, Aubertin M, Mbonimpa M (2007) Évaluation de l'effet du degré de saturation sur la diffusion et la consommation d'oxygène dans des résidus miniers sulfureux. In: Paper presented at the 60th CGC and 8th Joint CGS, pp 1431-1438

20. Hamdi J (2013) Mesures expérimentales des concentrations en oxygène sur le terrain et modélisations numériques pour évaluer le flux de diffusion dans la couverture du site minier LTA. (M.Sc.A.), Université du Québec en Abitibi-Témiscamingue

21. Hassani F, Archibald J (1998) Mine backfill, CD-ROM. Canadian Institute of Mine Metallurgy and Petroleum, p 263

22. Kleinmann RLP, Crerar DA, Pacelli RR (1981) Biogeochemistry of acid mine drainage and a method to control acid formation. Min Eng 33(3):300-305

23. Kossoff D, Dubbin WE, Alfredsson M, Edwards SJ, Mackin MG, Hudson-Edwards KA (2014) Mine tailings dams: characteristics, failure, environmental impacts, and remediation. Appl Geochem 51:229-245 
24. Maqsoud A, Mbonimpa M, Bussière B (2015) Hydrogeological behavior of mine tailings waste disposal using experimental test. Comptes-rendus de la conférence annuelle de l'International Mine water association (IMWA), conjointement à la 10e International Conference on Acid Rock Drainage (IMWA/ICARD), Santiago, Chili, pp 21-24

25. Maqsoud A, Neculita CM, Bussière B, Benzaazoua M (2015) Impact of fresh tailings deposition on the evolution of groundwater hydrogeochemistry at the abandoned Manitou mine site, Quebec, Canada. Environ Sci Pollut Res. 23(9):9054-9072

26. Marcus JJ (1997) Mining environmental handbook: effect of mining on the environment and American Environmental Controls on Mining. Imperial College Press, London

27. Martin V, Aubertin M, McMullen J (2006) Surface disposal of paste tailings. In: Thomas HR (ed) Proceedings 5th ICEG environmental geotechnics: opportunities, challenges and responsibilities for environmental geotechnics, 26-30 June, vol 2. Thomas Telford, Cardiff, pp 1471-1478

28. MEND. Mine Environment Neutral Drainage (2006) Paste backfilling geochemistry-environmental effects of leaching and weathering: Available at http://mend-nedem.org/wp-content/ uploads/2013/01/10.2.pdf. Accessed June 2016

29. Ouellet S, Bussière B, Mbonimpa M, Aubertin M (2006) Reactivity and mineralogical evolution of an underground mine sulphidic cemented paste backfill. Miner Eng 19:407-419

30. Shuttleworth JA, Thomson BJ, Wates JA (2005) Surface paste disposal at Bulyanhulu-practical lessons learned. In: Paper presented at the proccedings of the 8th international seminar on paste and thickened tailings-Paste 2005, Santiago, Chili

31. Simms P, Grabinsky MW and Zhan J (2005) Laboratory evaluation of evaporative drying from surface deposited tailings at the
Bulyanhulu gold mine. In: Paper presented at the 58th Canadian Geotechnical Conference, Saskatoon, Canada

32. Simms P, Grabinsky MW, Zhan J (2007) Modelling evaporation of paste tailings from the Bulyanhulu mine. Can Geotech J 44:1417-1432

33. Simms P, Grabinsky M (2009) Direct measurement of matric suction in triaxial tests on early-age cemented paste backfill. Can Geotech J 46(1):93

34. Singer PC, Stumm W (1970) Acidic mine drainage: the ratedetermining step. Science 167:1121-1123

35. Tacey W, Ruse B (2006) Making tailings disposal sustainable; a key business issue, Ch. 2. In: Jewell RJ, Fourie AB (eds) Paste and thickened tailings - a guide, 2nd edn. ACG, Perth

36. Theriault J, Frostiak J and Welch D (2003) Surface disposal of paste tailings at the Bulyanhulu gold mine, Tanzania. In: Paper presented at the proceedings (CD-ROM) of Sudbury mining environment conference, Sudbury, Ontario

37. Theron M, Addis PC, Wates JA and Martin V (2005) Bulyanhulu mine (Tanzania) paste tailings facility: relating the unsaturated properties of gold tailings to rateof rise. In: Proceedings of the 8th international seminar on paste and thickened tailings-paste 2005, Santiago, Chili

38. Yilmaz E (2010) Investigating the hydrogeotechnical and microstructural properties of cemented paste backfill using the cuaps apparatus. (Ph.D), Université du Québec en AbitibiTémiscamingue, Rouyn-Noranda, Canada

39. Yilmaz E, Benzaazoua M, Bussière B, Pouliot $S$ and Bernard B (2013) Hydrogeotechnical and geochemical characterization of surface paste disposal. In: Proceedings of the 23rd International Mining Congress and Exhibition of Turkey, Antalya, Turkey, pp $1815-1828$ 